\title{
PERFIL SANITÁRIO DE UNIDADES AGRÍCOLAS FAMILIARES PRODUTORAS DE LEITE CRU E ADEQUAÇÃ̃O À LEGISLAÇÃO VIGENTE
}

\author{
HEALTH PROFILE OF FAMILY AGRICULTURAL PRODUCER UNITS \\ OF RAW MILK AND THEIR ADJUSTMENT TO THE CURRENT LAW
}

\author{
Anna Christina de Almeida ${ }^{1 *}$ \\ Claudinei Alves dos Santos ${ }^{1}$ \\ Isabela Rocha Menezes ${ }^{1}$ \\ Lucas Magalhães Teixeira ${ }^{1}$ \\ João Paulo Ramos Costa ${ }^{1}$ \\ Rogério Marcos de Souza ${ }^{1}$ \\ ${ }^{1}$ Universidade Federal de Minas Gerais, Belo Horizonte, MG, Brasil. \\ *Autora para correspondência - aca2006@ica.ufmg.br
}

\begin{abstract}
Resumo
A região norte de Minas Gerais caracteriza-se por ser uma entre as regiões do país que têm o leite como um dos principais geradores de renda pela agricultura familiar. Para que o leite produzido tenha competitividade no mercado e tenha maior valor agregado, a agricultura familiar deve se adequar para atender os parâmetros legais vigentes. Teve-se como objetivo caracterizar o manejo produtivo geral adotado em unidades agrícolas familiares nos municípios de Bocaiúva, Francisco Sá e Montes Claros, no norte de Minas Gerais, identificando os entraves para a produção de leite dentro dos parâmetros estabelecidos pela legislação vigente. O sistema de produção foi avaliado por meio de coleta de dados em questionários e listas de verificação nos diferentes ambientes envolvidos com a produção. A qualidade microbiológica foi avaliada através da enumeração de microrganismos indicadores aeróbios mesófilos, psicrotróficos, Staphylococcus sp e coliformes fecais em leite cru, leite cru refrigerado, água e utensílios utilizados para produção. Os resultados da análise microbiológica associada às práticas de manejo adotadas revelaram que a principal causa da contaminação do leite era o emprego inadequado ou a ausência de boas práticas de higiene no sistema de produção, sendo este o principal entrave ao atendimento das exigências legais para o produto.
\end{abstract}

Palavras-chave: Boas Práticas Agropecuárias; Contaminação; Qualidade do leite.

\begin{abstract}
The northern region of Minas Gerais State is characterized as one of the regions of the country where milk has an important economic and social role for the family farming sector. Due to legal requirements, this sector must adjust so that the product will be marketed without bringing risk to the consumers, being, therefore, competitive on the commercial market. The objective of this study was to characterize the productive management generally adopted by the family farms in the municipalities of Bocaiuva, Capitão Enéas, Francisco Sá, and Montes Claros, in northern Minas Gerais, identifying the barriers to the production of milk within the parameters established by the legislation. The production system was evaluated by collecting data from questionnaires and checklists in the different environments involved with the production. The microbiological quality was assessed by enumeration of indicator microorganisms in aerobic mesophiles, psychrotrophic, Staphylococcus
\end{abstract}


sp and coliforms in raw milk, raw refrigerated milk, water and utensils used in the production. The results of microbiological analysis associated with the adopted practices revealed the main cause of milk contamination was the inadequate use or the lack of good hygiene practices in the production system, representing the main obstacle to attend the legal requirements for this product.

Keywords: contamination; Good Agricultural Practices; milk quality.

Enviado em: 07 junho de 2011

Aceito em: 04 março de 2016

\section{Introdução}

A agricultura familiar apresenta um universo bastante heterogêneo com disponibilidade de recursos, acesso ao mercado e capacidade de geração de renda, sendo a pecuária leiteira uma das principais atividades desenvolvidas. Diversos fatores como o fluxo de renda mensal, o fácil escoamento de produção, somados à possibilidade de exploração em áreas relativamente pequenas funcionam como atrativo para o setor, principalmente para o pequeno produtor ${ }^{(1)}$.

A produção de leite é tão disseminada na agricultura familiar, que a família, que já produz leite para o consumo interno, acaba destinando o excedente para comercialização ou processamento. A atividade leiteira vai além da alimentação familiar, permitindo a obtenção de renda mensal, que, em geral, é utilizada para as despesas domésticas. A atividade permite ainda o uso de terras não nobres devido à forma intensiva de produção adotada pela agricultura familiar. Por outro lado, a atividade leiteira tem uma grande importância na fixação das pessoas no campo, à medida que é a única atividade no meio rural que exige a presença de mão-de-obra todos os dias do ano, contribuindo para redução do êxodo $\operatorname{rural}^{(2)}$.

Um dos entraves para a agricultura familiar é a dificuldade na adoção de práticas de manejo recomendadas, visto que os costumes e a cultura acabam levando à resistência na adoção de novas tecnologias, ainda que estas sejam simples. Esta situação é observada em todos os tipos de produção, incluindo a cadeia leiteira.

Atualmente, existe consenso de que o controle da qualidade de leite utilizado como matéria-prima é fundamental para garantir a qualidade dos produtos derivados. A qualidade do leite cru é influenciada por múltiplas condições, entre as quais se destacam os fatores zootécnicos e aqueles relacionados à obtenção do produto. Os fatores zootécnicos incluem aspectos associados ao manejo, alimentação e potencial genético dos rebanhos e são responsáveis pelas características de composição do leite, bem como pela produtividade. Na fazenda, a ordenha constitui um dos pontos críticos de maior relevância para os animais e uma séria ameaça para a qualidade do leite. A higiene, a adequação dos equipamentos e os próprios funcionários podem levar a lesões internas da glândula mamária propiciando a invasão por microrganismos patogênicos. Como consequência, o rebanho passará a conviver com mastites, um dos principais fatores determinantes de prejuízos econômicos para o produtor e para a indústria de laticínios ${ }^{(3)}$.

A qualidade do leite cru no Brasil é considerada, em geral, insatisfatória associada às altas contagens de microrganismos aeróbios mesófilos, coliformes e psicrotróficos ${ }^{(3-7)}$. Rezende et al. ${ }^{(8)}$ avaliaram dados de analise de qualidade do leite cru refrigerado de três mesorregiões do Estado de Minas Gerais no período de 2006 e 2010 e os resultados indicaram a necessidade de adequação de técnicas para melhoria na qualidade do leite produzido. Matsubara et al. ${ }^{(7)}$ e Silva et al..$^{(9)}$ divulgaram resultados preocupantes quanto à qualidade do leite produzido por pequenos agricultores no agreste de Pernambuco, sendo identificado como fator de risco a não adoção de boas práticas de ordenha.

Este trabalho teve como objetivo caracterizar o sistema de produção adotado em unidades agrícolas familiares nos municípios de Bocaiúva, Francisco Sá e Montes Claros, no norte de Minas Gerais, identificando os entraves para a produção de leite dentro dos parâmetros estabelecidos pela legislação vigente. 


\section{Material e Métodos}

O trabalho foi conduzido adotando-se os princípios éticos aprovados pelo Comitê de Ética em Experimentação Animal da Universidade Federal de Minas Gerais, sob Protocolo n. 256/2010.

Para a realização deste trabalho, foram selecionados 59 estabelecimentos familiares produtores de leite distribuídos em três municípios do Norte de Minas, sendo: 20 no município de Bocaiúva, 14 em Francisco Sá e 25 em Montes Claros.

Foram realizadas visitas técnicas aos estabelecimentos e aplicaram-se questionários estruturados para o diagnóstico do manejo adotado nas propriedades. No questionário, avaliou-se a estrutura de produção, caracterização do rebanho e das instalações, manejo nutricional, manejo reprodutivo, manejo sanitário geral e práticas para prevenção e controle de mastite. Aplicou-se também um checklist, objetivando-se avaliar a adequação da estrutura produtiva ${ }^{(10)}$. O check-list foi estruturado em campos separados, constando de: curral de espera com três itens; sala de ordenha com treze itens; requisitos de higiene do local de produção com nove itens; higiene pessoal e requisitos sanitários com onze itens; armazenamento e higiene de transporte com quatro itens e defesa sanitária do rebanho com dez itens.

Foram coletadas 200 amostras de água, em unidades produtoras de leite nos municípios de Bocaiúva (68), Francisco Sá (55) e Montes Claros (77). As amostras foram coletadas em torneiras e em reservatórios nos locais de lavagem dos utensílios de ordenha e encaminhadas para pesquisa de coliformes fecais pela técnica do número mais provável ${ }^{(11)}$. No momento da coleta foram preenchidos questionários abordando características do reservatório, presença de rachaduras e ferrugem, frequência de limpeza e higienização, tratamentos e origem da água.

Coletou-se um total de 193 amostras de utensílios de ordenha nos municípios de Bocaiúva (63), Francisco Sá (55) e Montes Claros (75). Foram utilizados swabs estéreis imersos em água peptonada, conservados sob refrigeração após a coleta. Os swabs foram coletados em latões, baldes e teteiras após o término do processo de limpeza, sendo posteriormente encaminhadas ao laboratório de microbiologia onde se realizou a contagem de microrganismos aeróbios mesófilos. As amostras foram coletadas, analisadas e interpretadas seguindo a metodologia proposta por Compendium ${ }^{(11)}$. Avaliouse o atendimento dos parâmetros definidos na literatura de no máximo $100 \mathrm{UFC} / \mathrm{cm}^{2}$ de superfície. Os resultados foram separados em dois grupos, sendo Grupo $1-0 \leq$ contagem de mesófilos $\leq 100 \mathrm{UFC} /$ $\mathrm{cm}^{2}$ e Grupo 2 - contagem de mesófilos $>100 \mathrm{UFC} / \mathrm{cm}^{2}$.

Foram coletadas 326 amostras de leite in natura nos municípios de Bocaiúva (91), Francisco Sá (88) e Montes Claros (147). As amostras foram coletadas diretamente no latão após a ordenha ou em tanques de expansão, sendo acondicionadas em frascos estéreis e encaminhadas ao laboratório para realização das análises. Em cada etapa, coletaram-se duas amostras, sendo uma de leite recémobtido e outra de leite refrigerado. O leite recém-obtido representava a contaminação inicial do leite, sendo coletado diretamente nos latões, ou imediatamente após a refrigeração. Utilizou-se apenas leite proveniente da ultima ordenha. O leite refrigerado passava por 48 horas de refrigeração sendo analisado após esse período e representava a contagem do leite no momento da coleta pelos laticínios, que nas propriedades em questão era realizada a cada dois dias. Determinou-se a contagem de microrganismos psicrotróficos (PSI) no leite seguindo-se a metodologia descrita em Compendium ${ }^{(11)}$. O grau de crescimento de unidades formadoras de colônias (UFC) foi classificado em: baixo (UFC/mL $<100)$, médio $(100 \leq \mathrm{UFC} / \mathrm{mL}<10.000)$ e alto $(\mathrm{UFC} / \mathrm{mL} \geq 10.000)$.

Avaliou-se também a presença de microrganismos mastitogênicos a partir das amostras de leite cru com e sem refrigeração utilizando-se a metodologia descrita por Brito et. al ${ }^{(12)}$.

As coletas de todas as amostras foram realizadas em quatro épocas distintas do ano, com intervalo de três meses entre cada coleta. As análises das amostras coletadas foram realizadas no laboratório de microbiologia aplicada do Instituto de Ciências Agrárias da Universidade Federal de Minas Gerais. 
A composição do leite foi avaliada verificando-se o atendimento aos parâmetros mínimos exigidos pela IN-62 ${ }^{(10)}$. Os dados foram fornecidos pelos laticínios com os quais os produtores envolvidos neste trabalho comercializavam sua produção. Os resultados foram avaliados verificando-se o atendimento individual dos teores de proteína, gordura, lactose, extrato seco desengordurado, contagem bacteriana total e contagem de células somáticas exigidos pela legislação vigente ${ }^{(10)}$. Foram analisados os resultados de 45 amostras em Montes Claros, 78 em Bocaiuva e 42 em Francisco Sá.

Os resultados obtidos nos questionários foram tabulados e estudados por meio de estatística descritiva. Para análise da frequência de contaminação, utilizou-se estatística descritiva percentual por meio do procedimento do PROC/FREQ do pacote estatístico Statistical Analisys System.

\section{Resultados e Discussão}

A maior parte das propriedades acompanhadas neste estudo pode ser caracterizada como de baixa a média produção, já que $31(52,54 \%)$ relataram que possuíam uma produção média diária de até $100 \mathrm{~L}$ de leite. O quadro mostrou-se bastante similar ao observado em outras regiões do Brasil ${ }^{(13,14)}$.

A produtividade média por animal era baixa, sendo 8,4 L/vaca/dia no município de Bocaiúva, 7,7 no município de Francisco Sá e 5,0 nas propriedades de Montes Claros. Os menores índices de produtividade foram observados em Montes Claros, onde $82,5 \%$ das propriedades apresentavam produção diária abaixo de $100 \mathrm{~L} /$ dia. Outro indicativo da baixa produtividade é que a maioria das propriedades realiza ordenha apenas uma vez ao dia (50,8\%). Essa característica foi observada principalmente nos municípios de Montes Claros $(75,0 \%)$ e Francisco Sá $(50,0 \%)$, onde se observou menor produtividade animal/dia. Fernandes et al. ${ }^{(15)}$ afirmaram que a sustentabilidade de um sistema de produção leiteira perpassa pela aquisição/desenvolvimento tecnológico, visando manter a atividade produtiva, seja na agricultura familiar seja na empresarial. Silva et al. ${ }^{(9)}$ observaram médias de produção animal semelhantes às deste trabalho em rebanhos em que eram adotados duas ordenhas diárias.

A baixa produtividade observada pode ser justificada ainda pela ausência de raças ou cruzamento próprios para a produção de leite nas propriedades abordadas. No município de Bocaiúva, 20,0\% (4) das propriedades utilizavam cruzamentos envolvendo a raça Nelore. Nos municípios de Francisco Sá e Montes Claros, 50,0\% (7) e $68 \%$ (17) dos produtores utilizavam este tipo de cruzamento, respectivamente. Resultados semelhantes ao encontrado neste trabalho foram obtidos por Torres et. al. ${ }^{(13)} \mathrm{em}$ levantamento realizado em 110 propriedades familiares distribuídas no Norte de Minas e Vale do Jequitinhonha. Os autores relataram que cerca de uma em cada três propriedades leiteiras utilizam touros Nelores no rebanho. A raça Holandês estava presente em algum grau de sangue na maioria das propriedades, sendo que apenas em 16,0\% (4) das propriedades acompanhadas no município de Montes Claros a raça não estava presente.

Em relação à escrituração zootécnica, foram observadas deficiências em 81,35\% (48) do total de propriedades. As frequências de propriedades que não realizam o controle zootécnico do rebanho nos municípios foram 55,0\% (11) no município de Bocaiúva, 14,28\% (2) em Francisco Sá e 92 \% (23) em Montes Claros. O controle reprodutivo não era realizado em $45,76 \%$ (27) das propriedades, sendo os índices por município de 40\% (8) em Bocaiúva, 42,9\% (6) em Francisco Sá e 44,0\% (11) em Montes Claros. Observou-se menor frequência dessa prática em propriedades de menor produção.

O controle zootécnico permite o manejo adequado do rebanho, assim como o uso da capacidade máxima instalada e a obtenção de uma melhor rentabilidade na atividade leiteira ${ }^{(16)}$. Os autores ${ }^{(16)}$ relataram ainda que é preciso que os produtores de leite adotem práticas de gestão fundamentadas no planejamento da produção, organização rural e controle de atividades e processos, notadamente controle zootécnico e administrativo.

Em relação ao manejo sanitário, observou-se que em todas as propriedades eram realizadas as vacinações sistemáticas exigidas pela legislação. A realização de exames de tuberculose e brucelose periódicos era prática comum em apenas $1,6 \%$ das propriedades (uma) no município de Bocaiúva. A maioria 
dos produtores relatou não exigir certificado negativo para tuberculose e brucelose na aquisição de animais, aspecto já observado por Belchior ${ }^{(17)} \mathrm{em}$ rebanhos tecnificados no estado de Minas Gerais e por Monteiro et al. ${ }^{(14)}$ no agreste de Pernambuco. Os dados encontrados neste estudo são preocupantes mediante relato de consumo do leite e derivados elaborados sem tratamento térmico pelas famílias envolvidas nos sistemas de produção.

O maior problema sanitário relatado pelos produtores foi a pododermatite em $13,55 \%$ (8) das propriedades. De acordo com Ramos ${ }^{(13)}$, a higiene precária das instalações, o excesso de umidade, a utilização de cascalho nas vias de acesso ou dentro dos estábulos e a presença de irregularidades nos pisos foram considerados possíveis fatores predisponentes para o desenvolvimento das lesões de casco. Como agravante, cita-se a não adoção de medidas preventivas como casqueamento e a utilização de pedilúvio por parte da maioria dos produtores questionados. Esses fatores foram observados em todas as propriedades que relataram a ocorrência de pododermatite neste trabalho.

O tipo de ordenha adotado na maioria das propriedades (74.0\%) era o manual com a presença do bezerro, sendo 14 propriedades (70\%) em Bocaiúva, 12 (85,7\%) em Francisco Sá e 23 (92\%) em Montes Claros. Dados semelhantes foram relatados por Silva et al. ${ }^{(9)}$. Fagan et al. ${ }^{(19)}$ relataram que a adoção de ordenha mecânica não indica necessariamente uma melhoria na qualidade do leite produzido. a qualidade da higienização dos equipamentos e a contaminação inicial podem ser determinantes na qualidade do leite. Brito et al. ${ }^{(20)}$ observaram que um pequeno aumento no grau de contaminação dos tetos após o bezerro mamar pode ser reduzido com pré-dipping. Silva et al. ${ }^{(9)}$ relataram que o bezerro foi útil em situações de ordenha que não possibilitavam a higienizaçao dos tetos com retirada do leite em piquetes. Pesquisas em outros países têm relatado resultados satisfatórios na redução da mastite através do acesso do bezerro ao leite residual ou amamentação restringida, em rebanhos de menor produção ${ }^{(21-23)}$.

Foram observadas falhas quanto à adoção de boas práticas no manejo de ordenha (Tabela 1), com baixa frequência de limpeza e secagem dos tetos assim como na realização de pré-dipping e pósdipping.

Tabela 1. Frequência relativa e absoluta de propriedades por município quanto à adoção de boas práticas relacionadas ao manejo de ordenha

\begin{tabular}{lllll}
\multicolumn{1}{c}{ Município } & \multicolumn{1}{c}{$\begin{array}{c}\text { Limpeza de } \\
\text { tetos }\end{array}$} & $\begin{array}{c}\text { Secagem com } \\
\text { papel toalha }\end{array}$ & Pré-dipping & Pós-dipping \\
\hline Bocaiúva & $45,0 \%(9)$ & $25,0 \%(5)$ & $35,0 \%(7)$ & $30,0 \%(6)$ \\
Francisco Sá & $42,8 \%(6)$ & $21,4 \%(3)$ & $28,6 \%(4)$ & $28,6 \%(4)$ \\
Montes Claros & $8,0 \%(2)$ & $8,0 \%(2)$ & $16,0 \%(4)$ & $8,0 \%(2)$ \\
\hline
\end{tabular}

Segundo Amaral et al. ${ }^{(24)}$, a superfície dos tetos representa uma importante fonte de contaminação do leite e a lavagem com água clorada a $150 \mathrm{ppm}$ e a desinfecção antes da ordenha contribui, significativamente, para a redução de coliformes totais, microrganismos mesófilos e Staphylococcus $\mathrm{sp}$ e, consequentemente, para o controle de doenças. Guerreiro et al. ${ }^{(25)}$ relataram que a utilização de práticas de pré-dipping, pós-dipping, secagem dos tetos com papel toalha associadas à higiene adequada dos ordenhadores, do ambiente e do equipamento de ordenha levam a diminuições significativas na contagem total de bactérias psicrotróficas, reduzindo perdas na qualidade do leite. Matsubara et al. ${ }^{(7)}$, no agreste de Pernambuco, observaram resultados com redução de 99,9\% de aeróbios mesófilos em leite proveniente de rebanhos com ordenha manual com bezerro ao pé, com adoção de práticas de descarte dos primeiros jatos de leite e imersão dos tetos em solução clorada.

Em relação à limpeza do ambiente de ordenha, durante as visitas técnicas foram observadas condições precárias em 49,15\% (29) das 59 propriedades avaliadas. A maioria dos produtores $(37 / 62,71 \%)$ afirmou não realizar raspagem das fezes do ambiente de ordenha com regularidade. Os resultados mais críticos foram observados nos municípios de Montes Claros e de Francisco Sá, em que 79,16\% (19) 
e 78,57\% (11) dos produtores, respectivamente, afirmaram raramente retirar o excesso de esterco das instalações.

Do total de amostras coletadas dos utensílios, a maioria (75,7\%) apresentou crescimento de mesófilos acima de $100 \mathrm{UFC} / \mathrm{cm}^{2}$ de superfície, sendo 79,4\% das amostras coletadas em Montes Claros, 72,7\% (40) em Francisco Sá e 72,4\% (55) em Bocaiúva. Os maiores índices de contagem de mesófilos aeróbios nas superfícies de utensílios foram observados em propriedades de menor produtividade.

Estes dados são muito preocupantes, pois a contagem bacteriana total do leite pode aumentar significativamente quando em contato com equipamentos cuja limpeza é deficiente, uma vez que os microrganismos se proliferam nos resíduos de leite presentes na superfície dos recipientes e/ou utensílios de ordenha, assim como no próprio tanque de refrigeração do leite. Portanto, é imprescindível que a higienização dos equipamentos, principalmente daqueles que entram em contato direto com o leite, seja realizada de forma adequada ${ }^{(4)}$. Matsubara et al. ${ }^{(7)}$ e Silva et al ${ }^{(9)}$ observaram redução significativa na contagem de aeróbios mesófilos de teteiras quando se higienizavam os tetos e também no leite total quando se higienizavam corretamente baldes e latões.

Quanto à análise da água, as amostras foram coletadas no local de lavagem dos equipamentos de ordenha em torneiras $(91,5 \%)$ ou diretamente dos reservatórios (8,5\%). Foram analisadas 200 amostras de água, sendo que apenas seis $(3,0 \%)$ apresentaram-se fora do padrão com a presença de coliformes fecais ${ }^{(26)}$. Matsubara et al. ${ }^{(7)}$ e Silva et al. ${ }^{(9)}$ encontraram resultados semelhantes no agreste de Pernambuco.

Aágua era oriunda de poços artesianos em 93,0\% das propriedades em Francisco Sá, 90\% em Bocaiúva e $89,65 \%$ em Montes Claros. Conboy e Goss ${ }^{(27)}$ afirmaram que a deposição diária de resíduo orgânico animal no solo aumenta o risco de contaminação das águas subterrâneas. Vale ressaltar que a maioria dos poços artesianos são construídos em áreas baixas e não apresentam nenhum tipo de proteção e, portanto, estão sujeitos ao acúmulo de água de escoamento superficial contaminadas com resíduos orgânicos.

Não foram observadas práticas para proteção das fontes de água em nenhuma das propriedades analisadas. A maioria das amostras $(95,0 \%)$ apresentava bom aspecto em relação à aparência e cheiro. Ressalta-se que a água mesmo cristalina e aparentemente própria para o consumo pode estar contaminada por microrganismos patogênicos, podendo contaminar os utensílios de ordenha e ate mesmo o leite. Em relação aos reservatórios, observou-se que a maioria apresentava tampa, sendo 85,0\% (17) em Bocaiúva, 75,0\% (10) em Francisco Sá e 73,9\% (19) em Montes Claros. Ressalta-se que a ausência de tampa nos reservatórios constitui fator de risco, pois favorece a contaminação da água, permitindo a entrada de insetos entre outros contaminantes. A limpeza dos reservatórios era realizada variando entre uma e duas vezes ao ano, o que prejudica a qualidade da água utilizada nas propriedades.

Os resultados obtidos levam a considerar a água utilizada nos três municípios como fator de risco, podendo servir como fonte de contaminação do leite e de equipamentos, representando também risco à saúde dos seus usuários. Ressalta-se que, na maioria das propriedades, não se realiza o tratamento adequado da água, apenas em Francisco Sá (25\%) e Montes Claros (8,7\%) faz-se a utilização de cloro. Apenas uma propriedade, no município de Francisco Sá, dispunha de água tratada do serviço público. A água tem grande importância na cadeia produtiva do leite, sendo importante que sua origem tenha qualidade para sua utilização na cadeia leiteira ${ }^{(28)}$.

Do total de propriedades, 25 (42,37\%) utilizavam tanques de expansão comunitários, sendo seis no município de Francisco Sá e 19 no município de Montes Claros. Esses dados são superiores aos encontrados por Silva et al..$^{(9)}$ e Monteiro et al. ${ }^{(14)}$, em propriedades com características semelhantes, em que a maioria não refrigerava o leite. A utilização de tanques comunitários é uma alternativa para pequenos produtores; contudo, a prática carece de cuidados para evitar que falhas individuais comprometam a qualidade do leite refrigerado ${ }^{(29)}$. Além disso, a constante entrada de leite em temperatura ambiente no tanque pode levar a uma redução na eficiência da refrigeração ${ }^{(9)}$.

Em relação à contaminação por microrganismos psicrotróficos, a maioria das amostras de leite apresentou contagem dentro da classe de baixo crescimento (inferior a $100 \mathrm{UFC} / \mathrm{mL}$ ), sendo 69\% para o leite recém-obtido (106 amostras) e 58,6\% para o leite cru refrigerado (119 amostras). Dentro da 
classe de contagem alta, ou seja, superior a $10^{4}$, os resultados para o leite recém obtido e refrigerado foram respectivamente $5,8 \%$ (9 amostras) e 25,1\% (51 amostras). Os resultados mais críticos para o leite recém-obtido foram observados em Bocaiúva, onde 16,1\% (5) das amostras apresentaram contagem de PSI acima de $10^{4} \mathrm{UFC} / \mathrm{mL}$. Pinto et. al. ${ }^{(5)}$ consideram que contagens de psicrotróficos a partir de $10^{5}$ a $5 \times 10^{5}$ UFC já são suficientes para provocar perdas significativas na composição do leite. Silva et al..$^{(9)}$ encontraram aumento na contagem de microrganismos psicrotróficos no leite após refrigeração. Ressalta-se que foram observadas falhas na higienização do local de ordenha na maioria das propriedades com resultados acima dos limites estabelecidos. Não ocorreram diferenças significativas entre as médias obtidas em propriedades com diferentes volumes de produção diários, o que sugere que, mesmo em propriedades com maior produção, ainda ocorrem algumas deficiências higiênicas no processo produtivo. Arcuri et al..$^{(4)}$ relataram que o número de bactérias psicrotróficas presentes no leite cru está relacionado às condições higiênicas na produção, ao tempo e à temperatura em que o leite é armazenado.

A presença deste grupo de bactérias implica em grandes perdas econômicas para a indústria devido à ação proteolítica das enzimas produzidas que interferem no rendimento industrial com geleificação do leite UHT e aumento na taxa de sedimentação ${ }^{(30)}$, redução do rendimento em queijos ${ }^{(2)} \operatorname{com}$ comprometimento da qualidade, redução da vida de prateleira e consequentes prejuízos para indústria ${ }^{(9)}$.

Em relação à mastite, foram observadas falhas na adoção de práticas para diagnóstico e controle. Apenas nove $(15,25 \%)$ das 59 propriedades adotavam a linha de ordenha e estas utilizavam ordenha mecânica. Observa-se que esta prática não é comum em propriedades com sistema de ordenha manual ${ }^{(7,9,14)}$. A maioria dos produtores afirmou que utilizam apenas o diagnóstico "visual" da mastite; no entando, ressalta-se que este método não é eficiente, permitindo identificar apenas quadros mais agudos. Busato et al. ${ }^{(31)}$ relataram que a mastite é responsável por cerca de $25 \%$ das perdas econômicas envolvendo enfermidades no setor leiteiro, sendo que a forma clínica representa $18 \%$ do prejuízo total, por causar morte ou descarte prematuro da vaca, e que a redução na produção total é representada principalmente pela mastite subclínica $(82 \%)$. Além disso, compromete a qualidade do leite por determinar sérias alterações na composição, devido à diminuição na gordura, lactose, caseína, cálcio e fósforo. Esses resultados reforçam a importância da realização dos testes de CMT e caneca telada em conjunto e regularmente, prática observada em apenas nove propriedades deste estudo (Tabela 2).

Tabela 2. Relações de propriedades quanto à realização de medidas para diagnóstico e controle de mastite em município no Norte de Minas Gerais

\begin{tabular}{lcccc}
\hline Município & CMT & $\begin{array}{c}\text { Caneca } \\
\text { telada }\end{array}$ & $\begin{array}{c}\text { CMT e Caneca } \\
\text { Telada }\end{array}$ & $\begin{array}{c}\text { Linha de } \\
\text { ordenha }\end{array}$ \\
\hline Bocaiúva & $25,0 \%(5)$ & $35,0 \%(7)$ & $10,0 \%(2)$ & $30,0 \%(6)$ \\
Francisco Sá & $28,6 \%(4)$ & $14,3 \%(2)$ & $14,3 \%(2)$ & $7,2 \%(1)$ \\
Montes Claros & $8,0 \%(2)$ & $8,0 \%(2)$ & $20,0 \%(5)$ & $4,0 \%(1)$ \\
\hline
\end{tabular}

Em relação aos microrganismos mastitogênicos, Staphylococcus sp. foi isolado em 9,05\% (36) do total de amostras analisadas. As espécies identificadas foram $S$. aureus $(52,8 \%), S$. intermedius $(5,6 \%), S$. haemolyticus $(19,4 \%)$ e $S$. saprophyticus $(22,2 \%)$. Ericsson et al. ${ }^{(32)}$ relataram que a espécie $S$. aureus é considerada um patógeno primário e tem sido o agente mais frequentemente isolado em quadros de mastite bovina tanto de infecções clínicas como subclínicas. Acrescentaram ainda que S. intermedius é um microrganismo saprófito, normalmente isolado de amostras de pele, mas que mesmo assim pode causar a inflamação da glândula mamária.

Houve maior incidência de Staphylococcus sp. nas amostras coletadas durante o período chuvoso $(88,9 \%)$, sendo isolados $1,1 \%$ no mês de novembro e $77,8 \%$ em fevereiro. A maior incidência de microrganismos do gênero neste período está relacionada, provavelmente, às deficiências no manejo 
adotado durante a ordenha, como falhas na higienização das tetas, ou ainda, a quadros de mastite nos rebanhos envolvidos, conforme apresentado neste trabalho.

Microrganismos do gênero Staphylococcus sp. foram isolados em maior frequência em amostras de leite coletadas no município de Bocaiúva, sendo encontradas em 22,0\% (20) do total de amostras coletadas ao longo do trabalho. Todas as cepas foram isoladas em amostras coletadas em novembro e fevereiro. Ressalta-se que foram observadas falhas na higienização do ambiente de ordenha em 50\% das propriedades acompanhadas no município. Em relação a microrganismos do gênero Streptococcus sp., não foi isolada nenhuma cepa nas amostras analisadas.

Entre os microrganismos Gram negativos, a maioria foi Enterobacter sp., correspondendo a 35,39\%, seguido de Shigella sp. $(18,13 \%)$ e E. coli $(9,07 \%)$. Pesquisas em que se analisou o leite de latões apresentaram resultados semelhantes aos deste estudo quanto à presença de bactérias do grupo coliformes. A presença desses microrganismos pode estar relacionada com contaminação a partir do ambiente onde os animais eram criados, do ambiente de ordenha, da superfície do teto do animal, dos equipamentos, dos acessórios e utensílios de ordenha ${ }^{(4,9,32,33)}$, visto que os coliformes são considerados indicadores de contaminação do ambiente e resíduos de fezes ${ }^{(34)}$.

Os principais fatores de risco para ocorrência de mastite envolvem características dos animais, manejo inadequado, inexistência de treinamento dos ordenadores, não utilização de serviços laboratoriais para identificação dos patógenos e uso de equipamentos de ordenha sem manutenção periódica. A prática de diagnóstico precoce da mastite, a utilização de linha de ordenha, a implantação de tratamentos de vacas secas juntamente com a intervenção criteriosa em casos clínicos estão correlacionados com rebanhos que apresentam mastites em baixos níveis ${ }^{(33,35)}$.

Em todos os municípios, observou-se alta frequência de amostras fora dos padrões quanto à contagem bacteriana total expressa em UFC/mL (Tabela 3). Estes dados podem ser associados ao manejo inadequado, indicando associação entre as falhas na adoção das práticas higiênicas, a qualidade sanitária da água e dos utensílios utilizados na ordenha. Acuri et al..$^{(4)}$, Silva et al..$^{(9)}$ e Coentrão et al. ${ }^{(35)}$ encontraram associação entre altas contagens de mesófilos com práticas inadequadas de ordenha e presença de microrganismos mastitogênicos no leite de latões.

Tabela 3. Teores médios de proteína, gordura, extrato seco total, contagem de células somáticas (CCS) e unidades formadoras de colônias (UFC) em leite de rebanhos no norte de Minas Gerais

\begin{tabular}{|c|c|c|c|c|c|c|}
\hline Município & Resultados & $\begin{array}{c}\text { Gordura } \\
(\%)\end{array}$ & $\begin{array}{c}\text { Proteína } \\
(\%)\end{array}$ & ST (\%) & $\begin{array}{c}\mathrm{CCS} / \mathrm{mL} \\
\times 10^{3}\end{array}$ & $\begin{array}{c}\mathrm{UFC} / \mathrm{mL} \\
\times 10^{3}\end{array}$ \\
\hline \multirow{4}{*}{ 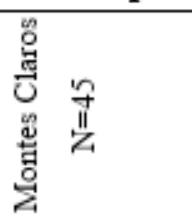 } & Média & 3,55 & 3,08 & 11,96 & 471,82 & 865,18 \\
\hline & Desvio padrão & 0,30 & 0,26 & 0,59 & 123,38 & 535,10 \\
\hline & Dentro padrão(\%) & 100 & 36 & 20 & 100 & 28,88 \\
\hline & Fora padrão (\%) & 0 & 64 & 80 & 0 & 71,11 \\
\hline \multirow{4}{*}{ 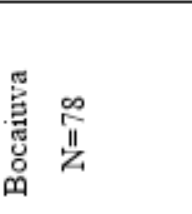 } & Média & 3,93 & 3,19 & 12,58 & 383 & 855 \\
\hline & Desvio padrão & 0,70 & 0.32 & 0,58 & 266,47 & 1401,30 \\
\hline & Dentro padrão(\%) & 96,15 & 85,90 & 100,0 & 91,03 & 19,5 \\
\hline & Fora padrão (\%) & 3,85 & 14,10 & 0 & 8,97 & 80,5 \\
\hline \multirow{4}{*}{ 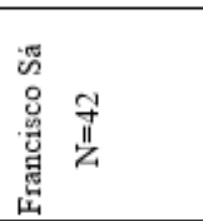 } & Média & 4,02 & 3,2 & 12,81 & 428 & 1219 \\
\hline & Desvio padrão & 157,5 & 0,146 & 0,25 & 348,68 & 0,08 \\
\hline & Dentro padrão(\%) & 73,81 & 97,62 & 100 & 76,19 & 28,58 \\
\hline & Fora padrão (\%) & 21,43 & 2,38 & 0 & 23,81 & 71,42 \\
\hline \multicolumn{2}{|c|}{ Padrão IN 62} & 3,0 & 2,9 & 12,4 & 600 & 300 \\
\hline
\end{tabular}

IN 62 = Instrução Normativa $62^{(10)} ; \mathrm{ST}=$ Sólidos totais; CCS= Contagem de Células somáticas; UFC= Unidades formadoras de colônias. 
A CCS esteve dentro dos padrões na maioria das amostras analisadas em todos os municípios, o que é descrito na literatura ao se analisar rebanhos não especializados, principalmente pela presença do bezerro no processo de ordenha, que contribui para a redução dos índices de mastite ao ter acesso ao peito após a ordenha ${ }^{(36)}$.

Gonzales et al. ${ }^{(37)}$ analisaram a influência de fatores nutricionais e raciais na composição do leite no Estado do Paraná e concluíram que existe influência da produção, do sistema de exploração e do sistema de ordenha sobre a CCS; animais mais produtivos possuem tendência a apresentar maior CCS e aspectos de manejo aliados ao aumento de produção podem influir na CCS. O grupo genético mostrou forte influência sobre os valores de CCS evidenciando que animais com maior produção e maior grau de sangue holandês apresentaram altas CCS, o que pode explicar os resultados encontrados neste trabalho em que foram utilizados animais cruzados com diferentes graus de sangue zebuíno.

Maior número de amostras que não atenderam ao padrão mínimo para o teor de gordura era do município de Francisco Sá $(21,43 \%)$ e para o teor de proteína era de Montes Claros (64\%). Em relação ao manejo nutricional, todas as propriedades adotam o sistema semi-intensivo. A alimentação durante a seca era composta por silagem de sorgo e cana de açúcar. Observou-se menor utilização de silagem de sorgo durante o período da seca por parte dos produtores do município de Montes Claros, em que 62,5\% (15) das propriedades utilizavam apenas cana de açúcar como suplementação.

Pesquisas mostram variação entre os teores de componentes do leite em função do manejo nutricional e de fatores raciais, o que justifica a variação entre as pesquisas assim como nos resultados obtidos neste trabalho. A concentração da gordura é fortemente influenciada pelo teor de fibra efetiva da dieta e pela relação volumoso/concentrado. Outros fatores como idade, condição corporal, fase da lactação, estresse térmico e contagem de células somáticas (CCS) podem alterar os teores desse sólido no leite ${ }^{(37)}$.

Os teores de proteína no leite são influenciados fundamentalmente pelo tipo de alimentação fornecida às vacas e pela concentração de carboidratos e proporções adequadas de aminoácidos. O estádio e o número da lactação também podem interferir no teor da proteína ${ }^{(38)}$.

Os resultados aqui obtidos apresentaram-se semelhantes em alguns critérios e diferentes em outros aos de trabalhos conduzido com rebanhos mestiços localizados na Região Sudeste do Brasil. Diferenças entre o manejo nutricional e sanitário dos rebanhos localizados em diferentes regiões do Brasil podem ter proporcionado diferentes magnitudes para a mesma fonte de variação dos componentes do leite e diferentes padrões de CCS do rebanho ${ }^{(37-40)}$, o que justifica a continuidade de trabalhos que visem à real interferência do sistema de criação de bovinos leiteiros adotados por agricultores familiares no norte de Minas e os entraves em atendimento à legislação vigente neste quesito.

As falhas no manejo estão entre os principais fatores limitantes à qualidade do leite principalmente com relação à contagem microbiana. Por outro lado, a ausência de práticas gerenciais, como o controle zootécnico, impede uma administração adequada, limitando o desenvolvimento da atividade e o investimento em melhorias no manejo geral. A correção destes fatores depende do estímulo ao produtor que, em todas as comunidades avaliadas, não recebe pela qualidade da produção. Há, ainda, o baixo preço pago pelo produto, levantado pela maioria dos produtores. Esses fatores desestimulam a busca por melhorias e, por consequência, comprometem a qualidade do leite produzido.

\section{Conclusão}

Conclui-se que os principais entraves na qualidade sanitária do leite estão relacionados a falhas envolvendo principalmente o manejo de ordenha e ausência de práticas gerenciais voltadas para a adoção de boas práticas agropecuárias.

O sistema de produção adotado nos municípios em estudo caracteriza-se por rebanhos mestiços com baixos níveis de produção, nível tecnológico baixo e com falhas no manejo sanitário, nutricional e 
reprodutivo dos rebanhos.

A qualidade nutricional do leite produzido apresenta variações no teor de gordura, de proteína e em sólidos totais, o que pode estar relacionado com o padrão racial e o manejo alimentar.

A contagem de bactérias no leite é alta em todos os municípios, já a contagem de células somáticas é baixa, assim como os índices de mastite nos rebanhos.

\section{Agradecimentos}

À FAPEMIG, PBEXT/UFMG, PRPq/UFMG e aos 59 estabelecimentos familiares produtores de leite nos municípios de Bocaiúva, Francisco Sá e Montes Claros, MG que possibilitaram a realização deste trabalho.

\section{Referências}

1. Santos CA. Qualidade do leite de rebanhos mestiços holandês e gir no norte de minas gerais e fatores de risco associados à mastite subclínica. Instituto de Ciências Agrárias, Universidade Federal de Minas Gerais, Montes Claros 2012. 91f. Dissertação de Mestrado, Montes Claros, MG. http://www.bibliotecadigital.ufmg.br/ dspace/bitstream/handle/1843/NCAP-97FQ8V/claudinei.pdf? sequence=1

2. Souza RP. As transformações na cadeia produtiva do leite e a viabilidade da agricultura familiar: o caso do sistema Coorlac. Universidade Federal do Rio Grande do Sul, Porto Alegre, RS. Dissertação de Mestrado, Porto Alegre, RS, 2007. http://www.lume.ufrgs.br/bitstream/handle/10183/11921/000619271.pdf?sequence=1

3. Nero LA, Mattos MR, Beloni V, Barros MAF, Pinto PAN, Andrade N J, et al. Leite cru de quatro regiões leiteiras brasileiras: perspectivas de atendimento dos requisitos microbiológicos estabelecidos pela Instrução Normativa 51. Ciência e Tecnologia de Alimentos. 2005;25(1):191-195. http://www.scielo.br/pdf/cta/v25n1/ a30v25n1.pdf

4. Arcuri EF, Silva PDS, Brito MAVP, Brito JRF, Langel CC, Magalhães MMA. Contagem, isolamento e caracterização de bactérias psicotrópicas contaminantes de leite cru refrigerado Arquivo Brasileiro Medicina Veterinária Zootecnia. 2006;58(3): 440-446. http://www.scielo.br/pdf/cr/v38n8/a25v38n8.pdf

5. Pinto CLO, Martins ML, Vanetti MDC. Qualidade microbiológica de leite cru refrigerado e isolamento de bactérias psicotrópicas proteolíticas. Ciência e Tecnlogia de Alimentos. 2006; 26(3): 645-651. http://www. scielo.br/pdf/cta/v26n3/31769.pdf

6. Martins MEP, NicolauES, MesquitaAJ, Neves RBS, Arruda MT. Qualidade de leite cru produzidoe armazenado em tanques de expansão no estado de Goiás. Ciência Animal Brasileira. 2008; 9(4):1152-1158. https://www. revistas.ufg.br/index.php?journal =vet\&page $=$ article\&op=view\&path $\% 5 \mathrm{~B} \% 5 \mathrm{D}=1829 \&$ path $\% 5 \mathrm{~B} \% 5 \mathrm{D}=4380$

7. Matsubara MT, Beloti V, Tamanini, R, Fagnani R, Silva LCC, Monteiro AA, et al. Boas práticas de ordenha para redução da contaminação microbiológica do leite no agreste Pernambucano. 2011;32(1):277-286. http:// www.uel.br/revistas/uel/index.php/semagrarias/article/view/3283

8. Rezende ESJ, Pinto SM, Pereira JLAR, Labigalini I. Qualidade higiênico-sanitária do leite cru em três mesorregiões de Minas Gerais. Revista do Instituto de Laticínios Cândido Tostes. 2012; 387(67): 64-69. http:// dx.doi.org/10.5935/2238-6416.20120051

9. Silva LCC, Beloti V, Tamanini R, Ovidio L, Mattos MR, Arruda AMCT et al. Rastreamento de fontes da contaminação microbiológica do leite cru durante a ordenha em propriedades leiteiras do Agreste Pernambucano. Semina: Ciências Agrárias. 2011;32(1):267-276. http://www.uel.br/revistas/uel/index.php/semagrarias/article/ view/3279 
10. Brasil. Ministério da Agricultura, Pecuária e Abastecimento. 2011. Instrução normativa n.62. Diário Oficial da União, $\mathrm{n}^{\circ}$ 251, p.6-11, seção 1. http://sistemasweb.agricultura.gov.br/sislegis/action/ detalhaA to.do? method $=$ gravarA to PDF \& tipo $=I N M \&$ numroA to $=00000062 \&$ seqA to $=000 \& v a l$ or $\underline{\mathrm{Ano}}=2011 \&$ orgao $=$ MAPA\&codTipo $=\&$ desItem

11. Compendium of Methods for the Microbiological Examination of Foods. Salfinger Y, Tortorello L (Ed.) 2015. American Public Health Association. http://ajph.aphapublications.org/doi/abs/10.2105/MBEF.0222.001

12. Brito MAVP, Brito JRF, Ribeiro, MT, Veiga VMO. Padrão de infecção intramamária em rebanhos leiteiros: exame de todos os quartos mamários das vacas em lactação. Arquivo Brasileiro Medicina Veterinária Zootecnia. 1999;51(2):129-135. http://dx.doi.org/10.1590/S0102-09351999000200001

13. Torres RA. Tecnologias para o desenvolvimento da pecuária de leite familiar do Norte de Minas e Vale do Jequitinhonha. Juiz de Fora: Embrapa Gado de Leite. 2007, 294p. portal.mda.gov.br/o/893835

14. Monteiro AM, Tamanini R, Cavaletti LCS, Mattos MR, Magnani FM, Ovidio L, et al. Características da produção leiteira da região do agreste do Estado de Pernambuco, Brasil. Semina: Ciências Agrárias. 2007; 28(4): 665-674. http://www.uel.br/revistas/uel/index.php/semagrarias/article/view/2901

15. Fernandes SAA, Faleiro AS, Ferrão SPB, Vieira VF, Souza DR, Nunes LR. et al. Perfil tecnológico de sistemas de produção de leite resfriado. Revista Brasileira de Saúde e Produção Animal. 2012; 13(1):01-12. http://www.scielo.br/pdf/rbspa/v13n1/a01v31n1.pdf

16. Fassio LL, Reis LP, Geraldo LG. Desempenho técnico e econômico da atividade leiteira em Minas Gerais. Ciência e agrotecnologia. 2006; 30(6):1154-1161. http://www.scielo.br/pdf/cagro/v30n6/a18v30n6.pdf

17. Belchior APC. Prevalência, distribuição regional e fatores de risco da tuberculose bovina em Minas Gerais. Escola de Veterinária, Universidade Federal de Minas Gerais, Belo Horizonte 2001. 55f. Dissertação de Mestrado, Dissertação de Mestrado, Belo Horizonte, MG, 2000. -. http://www.bibliotecadigital.ufmg.br/ dspace/handle/1843/BUDB-8BQFC2

18. Ramos LS, Silva LAF, Meirinhos MLG, Juliano RS, Prado LF, Cunha PHJ, et al. Avaliação de parâmetros reprodutivos em fêmeas bovinas de aptidão leiteira portadoras de pododermatite necrosante. Ars Veterinaria. 2001; 17(2):98-106. http://www.arsveterinaria.org.br/arquivo/2001/v.17,\%20n.2,\%202001/98-106.pdf

19. Fagan EP, Beloti V, Barros MF, Muller EE, Nero LA, Santana EHW, et al. Evaluation and implementation of good practices in main points of microbiological contamination in milk production. Semina: Ciências Agrárias. 2005;26(1):83-92. http://www.uel.br/proppg/portal/pages/arquivos/pesquisa/semina/pdf/semina 26 1119 11. pdf

20. Brito JRF, Brito MAVP, Verneque RS. Contagem bacteriana da superfície de tetas de vacas submetidas a diferentes processos de higienização, incluindo a ordenha manual com participação do bezerro para estimular a descida do leite. Ciência Rural. 2000; 30(5): 847-850. http://www.scielo.br/pdf/cr/v30n5/a18v30n5.pdf

21. Fröberg S, Aspegren-Güldorff A, Olsson I, Marin B, Berg C, Hernández C, et al. Effect of restricted suckling on milk yield, milk composition and udder health in cows and behaviour and weight gain in calves, in dual-purpose cattle in the tropics. Tropical Animal Health and Production. 2007; 39: 71-81. http://link. springer.com/article/10.1007\%2Fs11250-006-4418-0\#page-1

22. Fröberg S, Gratte E, Svennersten-Sjaunja K, Olsson I, Berg C, et al. Effect of suckling ('restricted suckling') on dairy cows' udder health and milk let-down and their calves' weight gain, feed intake and behavior. Applied Animal Behaviour Science. 2008; 113:1-14. http://dx.doi.org/10.1016/j.applanim.2007.12.001

23. González-Sedano M, Marin-Mejia B, Maranto MI, Leme de Magalhães-Labarthe AC, Alonso-Diaz MA. Effect of residual calf suckling on clinical and sub-clinical infections of mastitis in dual-purpose cows: 
Epidemiological measurements. Research in Veterinary Science. 2010; 89(3):362-366. doi:10.1016/j. rvsc.2010.04.002

24. Amaral LA, Romano APM, Nader Filho A, Rossi Junior OD. Qualidade da água em propriedades leiteiras como fator de risco à qualidade do leite e à saúde da glândula mamária. Arquivo do Instituto Biológico. 2004, 71(4):417- 421.

\section{http://www.biologico.sp.gov.br/docs/arq/V71 4/amaral.PDF}

25. Guerreiro PK, Fragoso MRM, Braga GC, Gasparino E, Franzener ASM. Qualidade microbiológica de leite em função de técnicas profiláticas no manejo de produção. Ciência e Agrotecnologia, v. 29, n. 1, p. 216-222, jan./fev. 2005. http://dx.doi.org/10.1590/S1413-70542005000100027

26. Brasil. Ministério da Saúde. Portaria n. ${ }^{\circ}$ 2.914, de 12 de dezembro de 2011. Dispõe sobre procedimentos de controle e de vigilância da qualidade da água para consumo humano e seu padrão de potabilidade. Diário Oficial da República Federativa do Brasil, Brasília, DF, Seção 1, 04 de janeiro de 2012, p. 43-49. http://bvsms. saude.gov.br/bvs/saudelegis/gm/2011/prt2914_12_12_2011.htmL

27. Conboy MJ, Goss MJ. Natural protection of groundwater against bacteria of fecal origin. Journal Contamination Hydrology. 2000; 43:1-24, 2000. doi:10.1016/S0169-7722(99)00100-X

28. Polegato EPS, Amaral LAA. qualidade da água na cadeia produtiva do leite: Nível de conhecimento do produtor rural. Higiene Alimentar. 2005; 19(129): 15- 24.

29. Bueno VFF, Mesquita AJ, Oliveira JP, Nicolau ES, Oliveira NA, Neves RBS, Mansur JRG Influência da temperatura de armazenamento e o sistema de utilização de tanque de expansão sobre a qualidade microbiológica do leite cru. Higiene Alimentar. 2004; 18(124): 62-67.

30. Topçu A, Numanoglu E, SaldamLi I, Proteolysis and storage stability of UHT milk produced in Turkey. International Dairy Journal. 2006; 16: 633-638. doi:10.1016/j.idairyj.2005.08.018

31. Busato A, Trachsel P, Schallibaum M, Blum JW. Udder health and risk factors for subclinical mastitis in organic dairy farms in Switzerland. Preventive Veterinary Medicine. 2000, 44: 205-220. doi:10.1016/S0167$\underline{5877(00) 00104-5}$

32. Ericsson UH, Lindberg A, Persson WK, Ekman T, Artursson K, Nilsson-Ost M, et al. Microbial aetiology of acute clinical mastitis and agent-specific risk factors. Veterinary microbiology. 2009;28(137):90-97. doi: 10.1016/j.vetmic.2008.12.005. Epub 2008 Dec 11.

33. Almeida AC, Mendes CPA, Silva DB. Fatores determinantes da ocorrência de mastite bovina, detectada em rebanhos através da análise de leite de latões. Higiene Alimentar. 2005;19(134):81-87.

34. Brito MAVP, Brito JRF, Portugal JAB. Identificação de contaminantes bacterianos no leite cru de tanques de refrigeração. Revista do Instituto de Laticínios Cândido Tostes. 2002;57:47-52.

35. Coentrão CM, Souza GN, Brito JRF, Brito MAVP, Lilenbaum W. Fatores de risco para mastite subclínica em vacas leiteiras. Arquivo Brasileiro de Medicina Veterinária e Zootecnia. 2008;60(2):283-288. http://www. scielo.br/pdf/abmvz/v60n2/a01v60n2.pdf

36 Oliveira JLP, Kozerski ND, Silva DR, Silva AV, Martins L A. Fatores de risco para mastite e qualidade do leite no município de Altônia -PR. Arquivos de Ciências Veterinárias e Zoologia da UNIPAR. 2013;16(1):6172.http://revistas.unipar.br/veterinaria/article/view/4485/2710

37. Gonzalez SG, Müller EE, Freitas JC, Godoy AL. Influência de fatores raciais e manejo nutricional na contagem de células somáticas e nos constituintes do leite de vacas holandesas e mestiças no Norte do Estado do Paraná, Brasil. Acta Scientiarum. Animal Sciences. 2003;25(2):323-329. 10.4025/actascianimsci.v25i2.2016 
38. Sancanari JBD, Ezequiel JMB, Galat RL, Vieira PF, Seixas JRC, Santamaria M, et al. Efeito da metionina protegida e não protegida da degradação ruminal sobre a produção e composição do leite de vacas Holandesas. Revista Brasileira de Zootecnia. 2001;30(1):286-294, 2001. http://www.scielo.br/pdf/rbz/ v30n1/5465.pdf

39. Gonzalez HL, Fischer V, Ribeiro, MER, Gomes JR, Stumpf Jr W, Fagundes MC, Silva MA. Avaliação da Qualidade do Leite na Bacia Leiteira de Pelotas, RS. Efeito dos Meses do Ano. Revista Brasileira de Zootecnia.2004;33(6):1531-1543. http://dx.doi.org/10.1590/S1516-35982004000600020

40. Gonzalez HL, Fischer V, Ribeiro, MER, Gomes JR, Stumpf Jr W, Fagundes MC, Silva MA. Comparação da qualidade do leite em diferentes sistemas de produção da bacia leiteira de Pelotas, RS, Revista Brasileira de Agrociência. 2006;12(4):475-482,2006. http://www2.ufpel.edu.br/faem/agrociencia/v12n4/artigo15.pdf 